\title{
Responding to Information Requests: The Case of Inscribed Object Checks
}

\author{
Kelly Katherine Frantz ${ }^{1}$ \\ Teachers College, Columbia University
}

\begin{abstract}
This paper explores one way that participants use inscribed objects in their immediate environment as resources for interaction. In particular, it identifies and analyzes a type of embodied response turn found in information request sequences. The data come from a video recording of family members engaged in a joint cooking activity, where they are preparing an unfamiliar dish while following recipe instructions. In this setting, participants and inscribed objects hold varying levels of epistemic rights and access regarding the task at hand. This appears to have consequences for how the interaction unfolds. As participants ask questions about the recipe, respondents repeatedly employ a particular embodied practice of checking and reading aloud the recipe, which I call an inscribed object check. An analysis of this practice and its sequential variations shows how participants draw on verbal, embodied, and environmental resources to fill knowledge gaps made relevant by information requests when the knowledge lies within inscribed objects. The findings contribute to our understanding of the role that inscribed objects play in interaction, as well as how responses to information requests are managed in everyday settings when all participants are relatively unknowledgeable about the task at hand.
\end{abstract}

Keywords: conversation analysis, embodiment, epistemics, information requests, preference, requests

\section{INTRODUCTION}

When we interact with others, we use our surroundings to help create meaning. Through embodied actions like gesture, point, and gaze, we engage with the world around us. A growing interest in the multimodal nature of talk-in-interaction (for overviews, see Mondada, 2016; Nevile, 2015; Streeck et al., 2011) has led to a particular focus on how participants utilize the

\footnotetext{
${ }^{1}$ Kelly Katherine Frantz is a doctoral student in Applied Linguistics at Teachers College, Columbia University. In her research, she uses conversation analysis to study writing tutoring, learning processes, and technology-mediated interaction. She currently works as a Doctoral Teaching Fellow at the Community Language Program and a writing consultant for the TC Graduate Writing Center. Correspondence should be sent to E-mail: kkf2109@tc.columbia.edu

(C) 2021 Frantz. This is an open access article distributed under the terms of the Creative Commons Attribution License, which permits the user to copy, distribute, and transmit the work provided that the original authors and source are credited.
} 
affordances of their environment to achieve actions in talk. Specifically, some researchers have studied the interactional role of artifacts in order to understand how objects in one's immediate environment can act as resources for interaction (e.g., Day \& Wagner, 2014; Goodwin, 2000; Mondada, 2011; Richardson \& Stokoe, 2014; for an overview, see Nevile et al., 2014). The present paper will focus on inscribed objects, also called written materials or inscribed artifacts, which can include items such as documents, books, signs, or computer screens, among others. Inscribed objects have been studied in various settings and have been shown to help speakers achieve myriad actions (e.g., Ford, 1999; Greer \& Leyland, 2020; Hamann, 2020; Svinhufvud \& Vehvilainen, 2013). Despite this growing research interest, there remains little understanding of the epistemic role that inscribed objects play in talk-in-interaction. Given that inscribed objects hold written information, there may be instances when speakers seek information that is not immediately available to the participants, but that can be found by referencing inscribed objects. One situation where this can occur is when participants are cooking and following an unfamiliar recipe. The present paper examines this environment, where participants hold relatively little knowledge of the task at hand compared to the inscribed objects (the recipe documents). In this study, I specifically focus on how inscribed objects are made relevant in information request sequences, exploring how these objects help participants respond to information requests and maintain progressivity in talk. Before moving into the present study, I will briefly review relevant literature on inscribed objects and information requests.

\section{REVIEW OF LITERATURE}

\section{The Role of Inscribed Objects in Interaction}

Studies of inscribed objects in institutional settings show how written materials can facilitate the performance of various tasks. For example, pilots use checklists to prepare to fly (Nevile, 2004), teachers use textbooks to plan lessons (Greer \& Leyland, 2020), office workers use written agendas to direct meetings (Nissi \& Lehtinen, 2015; Svennevig, 2012), archeologists use reference documents to classify items (Goodwin, 2000), and students use textbooks and worksheets to collaboratively complete assignments (Ford, 1999). Although covering a limited number of settings, studies like these reveal that orienting to written materials through practices like gaze shifts, pointing, or reading aloud, can have consequences for the turn-by-turn unfolding of talk. By making relevant written materials, participants can initiate a move into new activities or topics (Svennevig, 2012; Svinhufvud \& Vehvilainen, 2013), close down an activity (Mondada, 2006), or prompt a return to a prior activity (Deppermann et al., 2010; Greer \& Leyland, 2020). For example, in academic advising meetings, supervisors can mark a shift from small talk into the main advising activity by turning their gaze to the student's document (Svinhufvud \& Vehvilainen, 2013). In another example, teachers doing collaborative lesson planning can point to and read aloud from written materials to propose an initial plan or return to a plan when talk has gone off topic (Greer \& Leyland, 2020). In many of these examples, researchers show that inscribed objects help participants maintain progressivity in talk and, occasionally, achieve intersubjectivity. In other words, participants can use written materials in their immediate environments to keep conversations running smoothly and to help establish shared understandings. 
Particularly relevant to the present study is research on the role of inscribed objects in situations where one or more participants express a lack of knowledge. Hamann (2020) explored how information on a whiteboard and laminated card were made relevant in conversations between a brain injury patient and his therapist and nurse. Hamann showed that the presence of these written materials made possible certain sequential trajectories in the patient's rehabilitation sessions. Specifically, when the patient asked the question, "How long do I have to stay here?" the staff repeatedly directed his attention to the whiteboard or laminated card, which held the answer to this question as well as other basic information about the patient's situation. The patient could use these objects to help him access the requested information instead of the staff answering his question directly. This study aligns with research on dementia patients, which has shown that having access to written information allows the patients to more readily and smoothly engage in conversations (e.g., Bourgeois, 1990, 1992).

In addition to rehabilitation settings where knowledge gaps are a result of memory loss, educational settings have also offered interesting environments to explore how participants engage with inscribed objects when knowledge gaps emerge in interaction. Jakonen and Morten (2015), for instance, focused on what they call epistemic search sequences, where students working in groups made an information request, then worked collaboratively to find the answer. The researchers identified various linguistic and embodied practices that students used to close the knowledge gap, one of which was referencing written pedagogic materials. Particularly notable in this environment is that all members of the group had similar access to the task-based knowledge, which could explain the collaborative nature of these search sequences (Keevallik, 2011). Back's (2016) study of peer tutoring also explored epistemic search sequences, showing how a peer tutor drew on various resources to resolve her own and her tutee's lexical gaps. Interestingly, Back showed how the tutor tended to favor her own memory over information from written materials (e.g., Google searches) as one way to position herself as an expert on the topic. Underlying this research on the role of inscribed objects in situations where knowledge gaps are expressed are the notions of epistemic status and stance. Back (2016) and Jakonen and Morten (2015) address this explicitly, focusing on how knowledge is negotiated in interaction and occasionally mediated by inscribed objects. Hamann (2020), while not explicitly referencing epistemics, shows how the availability of knowledge in the form of written information makes the activity of answering a question possible. In the next section, I will briefly review epistemics in the context of information request sequences.

\section{Information Requests and Epistemics}

Participants' knowledge states and how they express them are highly relevant to how interactions unfold. Speakers adjust their talk based on their understanding of what their coparticipants know and don't know. For example, we might expect speakers to avoid announcing what their recipients already know. Similarly, we might expect speakers to only ask questions with the assumption that recipients have the knowledge to provide an answer. Put another way, participants constantly orient to others' epistemic statuses. Epistemic status refers to the agreed upon and generally stable states of participants' knowledge (Heritage, 2012, 2013). Heritage (2012, 2013) distinguishes epistemic status from epistemic stance, which is expressed momentby-moment through the design of turns. It is continually constructed, negotiated and shifting during interaction. The interplay of epistemic status and stance is evident, for example, when someone produces a turn with interrogative syntax. In order to determine whether this turn is 
asking an information-seeking question or performing another sort of action, recipients must consider the relative knowledge state of the speaker with regard to the topic. Is the speaker more knowledgeable $(\mathrm{K}+)$ or less knowledgeable (K-) than others in the interaction (Heritage, 2012)?

Information request sequences, the focus on the current paper, are particularly interesting when explored from the perspective of epistemics. When a speaker requests information, they assert their own lack of knowledge on the topic. At the same time, they make relevant the expectation that the addressed recipient has and will be able to provide the requested information (Heritage \& Raymond, 2012). Thus, inherent in information requests are claims about the epistemic statuses of the participants. We can understand the nature of this kind of sequence with reference to the structure of request sequences more broadly. Although there are many different kinds of requests and the request type determines the specific nature of the response, the requestresponse sequence can be generally understood in terms of its preference structure, where the preferred response to a request is the granting of the request (Pomerantz, 1984; Sacks, 1987). Depending on the nature of the request, this granting can be done immediately or deferred for a future time (Schegloff, 2007). Inability to grant the request is generally done in a dispreferred format, often accompanied by markers of trouble, such as pauses, accounts, or apologies. Conversation analytic studies on requests tend to focus on one of two main areas: how participants structure the request turns (e.g., Cekaite, 2010; Curl \& Drew, 2008) and how participants manage request rejection (e.g., Lee, 2011). Apart from some attention to request rejection, there remains limited research on the various forms that responses to requests take. For instance, only a small set of studies have explored different ways that participants structure preferred responses (e.g., Couper-Kuhlen et al., 2011; Sorjonen, 2001) or do embodied request granting (e.g., Rauniomaa \& Keisanen, 2012).

Regarding response design in information request sequences, specifically, responders generally have three options: they can provide a response, provide a nonanswer (e.g., "I don't know."), or provide no response at all (Heritage, 1984; Stivers, 2010; Stivers \& Robinson, 2006). When information requests take an interrogative syntax, as they often do, we can also call them information-seeking questions. These can be either $w h$ - or polar questions. Recent studies of responses to these question types have revealed that, in line with the research on request sequences reviewed above, participants treat informative responses as preferred over nonanswers and conditional answers (Clayman, 2002; Stivers \& Robinson, 2006; Robinson, 2020). Responses to $w h$ - questions fall into two general categories: phrasal and clausal (Fox \& Thompson, 2010). Whereas phrasal responses are fitted to and rely on the format of the original wh- question in order to be interpreted, clausal responses are less dependent on and can depart from the assumptions in the original question. Polar questions invite the respondent to either affirm or reject a proposition (Heritage \& Raymond, 2012; Pomerantz, 1988). When responding to polar questions, speakers can accept the terms of the question by providing a type-conforming response (e.g., "yes"; Raymond, 2003), a repetitional response (Heritage \& Raymond, 2012; Stivers, 2011), or a marked confirmation (e.g., "of course"; Stivers, 2011). Alternatively, respondents can challenge or adjust the terms of the question by giving a transformative response (Stivers \& Hyashi, 2010).

So far, we have established that participants orient to others' knowledge states, that inherent in information requests are claims about speaker and recipient knowledge, and that inability to provide the requested information is generally dispreferred. Given this, how can we explain cases where speakers ask questions to unknowing recipients? Jakonen and Morten's (2015) study of collaborative epistemic search sequences provides one example of this. Among 
peers with similar rights and access to task-based knowledge, students ask questions with the expectation that they will collaboratively arrive at the answer. Although Jakonen and Morten's data was collected from an educational setting, Keevallik (2011) claims that this shared responsibility to resolve knowledge gaps is especially characteristic of everyday settings, where there are less likely to be institutional structures that situate some individuals as more or less knowing than others. It is worth exploring, then, how responses to information requests are managed in everyday settings when all participants are relatively unknowledgeable about the task at hand. How are these responses managed when the epistemic rights lie primarily in an inscribed object, and what sequential consequences does this have for the interaction?

The present study explores a particular type of multimodal response to information request sequences in everyday settings where an inscribed object is made relevant. It aims to contribute to efforts to understand the management of epistemics across participants and objects, explore the use of inscribed objects in interaction, and specify a type of response turn in information request sequences. While Jakonen and Morten's (2015) study showed how inscribed objects provide one way to resolve information requests, they did not explore the sequential variations that these turns can take and their consequences for interaction. Relatedly, studies of inscribed objects more broadly have primarily focused on workplace settings, where epistemic statuses may be more fixed. To my knowledge, there has been no systematic look at the various turn structures that responses to information requests can take when epistemically-advantaged inscribed objects are made relevant in everyday talk.

The focal practice analyzed in this study is a response turn that is both embodied and verbal in nature, which I am calling inscribed object checks. They are employed in the context of a joint cooking activity, where participants are following instructions from an unfamiliar recipe, and someone asks an information-seeking question related to the task at hand. This is a particularly interesting setting within which to examine information requests and responses because of its fluid epistemic nature. While participants request recipe-related information from each other, they ultimately tend to orient to the recipe text itself as a resource to provide this information. This study will be guided by two research questions: What role do inscribed object checks play in information request sequences? And what sequential variations do turns with inscribed object checks take?

\section{DATA AND METHOD}

The data for this paper come from a 66-minute video and audio recording of three family members, Mom, Kara, and Jen, cooking in their kitchen (first names are pseudonyms). They are cooking a recipe that is new for all of them: a tomato shallot pasta. The recipe page is pulled up on Kara's phone, and they are also following instructions for cooking pasta, which is written on the back of the pasta box. Therefore, all three of the participants have a relatively unknowing status regarding the particular cooking task at hand, and no one has been clearly established as the lead or expert cook. In the participants' immediate environment, there are at least two inscribed objects (the tomato shallot pasta recipe and the pasta cooking instructions) which are treated as resources in the context of this joint cooking activity. This setting reflects the environment outlined by Keevallik (2011) where all members in the interaction have similar epistemic statuses toward the task at hand. In settings like this, information-seeking questions are likely to be interpreted as genuine requests for information (as opposed to rhetorical or known- 
answer questions), but they do not necessarily make claims about the recipients' knowledge states. Instead, they may initiate some kind of search for information.

The data were transcribed and analyzed using a conversation analytic framework (see Appendix A). After repeatedly viewing the recording and reading the transcript, I identified 35 instances of inscribed object checks. This practice occurs when (1) a participant's attention is clearly on an object where a recipe is written (in this case, a phone and the back of a pasta box), and (2) the participant says something related to the recipe. In all cases, the participant's gaze is focused on the recipe; in addition, participants are often either holding the recipe object close to their face or bending down toward it. The verbal component of this practice often appears as a partial verbatim reading out loud of the recipe. Other times, participants appear to put the recipe information in their own words. Of the 35 identified cases of this practice, 16 of them occur within an information request sequence, where one participant solicits information related to the recipe or cooking process. These 16 cases will be the focus of the present analysis.

\section{ANALYSIS}

Of the sixteen cases of inscribed object checks that occurred within an information request sequence, seven (44\%) of these recipe checks occurred as the immediate second pair part in the sequence. Nine $(56 \%)$ of them occurred, not in the immediate second pair part, but in some part of an expanded sequence, usually when the original response was marked unsatisfactory in some way. In the following analysis, I present two examples of the check occurring in the immediate next turn. Then I present two variations of expanded sequences where the check occurs later on. Taken together, these examples demonstrate the various ways participants employ inscribed object checks in response turns of information request sequences.

\section{Inscribed Object Checks in Immediate Next Turns}

In the following extract, a participant does an inscribed object check almost immediately following the initiation of an information request sequence. Before the extract begins, Mom is at the sink peeling an onion, and Kara is cutting garlic. Kara's phone is on the counter next to her. They are working in silence until Mom asks an information-seeking question about the recipe.

\begin{tabular}{|c|c|c|c|}
\hline \multicolumn{3}{|c|}{ ract 1: Dutch oven } & \multirow{3}{*}{$\begin{array}{l}>\text { D'you need< }<\text { a: (.) saute pan?=or: } \\
\text { wha'd'you need.= }\end{array}$} \\
\hline 01 & Mom: & & \\
\hline 02 & & & \\
\hline 03 & Kara: & $\rightarrow$ & $=$ gazes to phone $-\mathrm{u}: \mathrm{m}(0.5)$ reads-in a large heavy \\
\hline 04 & & $\rightarrow$ & bottomed $\uparrow \underline{\text { dutch oven. }}$ \\
\hline 05 & Mom: & & {$[\mathrm{I} \uparrow$ don't have, } \\
\hline 06 & Kara: & & [gazes at garlic \\
\hline 07 & & & \$hh\$ \\
\hline 08 & & & gazes at phone- $(0.2)$ \\
\hline 09 & Mom: & & starts walking across the kitchen-I'm a faii(h)lure \\
\hline 10 & & & [in the coo- eh $\uparrow \underline{\text { kitchen.] }}$ \\
\hline 11 & Kara: & & [\$个heh he he \\
\hline 12 & & & gazes at $M$-well [then $\$>$ I dunno $<$ what's an \\
\hline
\end{tabular}


13 Mom: $\quad$ [places hand on hip, gazes at cabinets

14 Kara: alternative.

$15 \quad(0.8)$

16 Mom: $\quad$ gazes at $K-<\mathrm{u}:: \mathrm{m}$,

$17 \quad$ gazes at cabinet, walks to cabinet

Mom initiates an information request sequence by asking a polar question and then revising it to a wh-question (line 01). Kara then immediately bends over the counter and shifts her gaze slightly to her phone while uttering "u:m" (line 03). There is a pause as Kara continues to gaze at her phone. Then she reads a phrase from the recipe out loud verbatim (see Appendix B), stressing the words "Dutch oven." Kara's response (lines 03 and 04) is an example of an inscribed object check. She initiates her turn both verbally and nonverbally: with a non-lexical perturbation ("um") and a slight body movement and gaze shift. This pre-beginning (Schegloff, 1996) signals her receipt of Mom's question and a move to respond to it; however, it also signals some minor trouble. Kara is not yet able to provide the information that Mom seeks. Delayed turn beginnings in response to questions can mark trouble related to epistemic authority (Fox \& Thompson, 2010; Heritage, 1998). In this case, we can see that Kara orients to her phone and her answer takes the form of direct language from the recipe, essentially positioning the recipe as the expert with the epistemic rights to answer Mom's question.

When Kara reads a phrase from the recipe out loud, she appears to drop the beginning of the sentence, whose full form is an imperative: "Heat olive oil in a large heavy bottomed Dutch oven" (See Appendix B). Instead, she speaks aloud only the final prepositional phrase, which more closely fits Mom's wh- question by providing the "what" being sought. It should be further noted that although Kara is borrowing words from the recipe, she stresses the noun phrase that most closely provides Mom with the requested information. This stress also marks a contrast between Mom's proposed cooking tool ("a sauté pan") and the one recommended by the recipe. As Fox and Thompson (2010) explain, phrasal responses to wh- questions (versus yes/no questions) are generally unmarked. They accept "the relevancies mobilized by the question" and provide the specific information requested (p. 420). In this case, although Kara signals minor trouble at the turn beginning, she eventually does a form of simple answering. Mom appears to treat Kara's answer as satisfactory in line 05 by moving on to present a related problem: she doesn't have a Dutch oven. The interaction proceeds as the participants treat Mom's comment as laughable and begin to problem solve.

Speakers can also do inscribed object checks in immediate next-turn responses to yes/no information-seeking questions. The following extract provides an example of this. It begins with Mom and Kara deciding on which type of pasta to use for the dish, which is something not specified in the recipe text.

\begin{tabular}{|c|c|c|}
\hline \multicolumn{3}{|c|}{ Extract 2: Serving size } \\
\hline 01 & Mom: & $>$ yeah I have < boxed spaghetti, or: \\
\hline 02 & & {$[$ walks toward $K$, gazing at box-(0.2)] this. $=$} \\
\hline 03 & Kara: & [gazes at $M$ \\
\hline 04 & Mom: & $=$ shows to $K$ \\
\hline 05 & & it's just [spaghetti. \\
\hline 06 & Kara: & [why don't we] do $\uparrow$ that one, \\
\hline 07 & Mom: & gazes at box-Yeah.= \\
\hline
\end{tabular}




\begin{tabular}{|c|c|c|}
\hline 08 & Kara: & $=$ gazes down -If we're gonna do $\uparrow$ fancy, \\
\hline 09 & Mom: & $\mathrm{mhm} ?=$ \\
\hline 10 & Kara: & $=$ let's do extra fancy. \\
\hline 11 & Mom: & gazing at spaghetti- $\uparrow$ yeah. $=$ \\
\hline 12 & Jen: & $=$ gazes at $M$-is there enough? \\
\hline 13 & Mom: $\rightarrow$ & gazes to back of box-(0.8) \\
\hline 14 & $\rightarrow$ & It says serving size three. \\
\hline 15 & & [gazes at $J]$ \\
\hline 16 & Jen: & {$[>$ okay.<] } \\
\hline 17 & Mom: & so, it won't be a huge [portion?] \\
\hline 18 & Jen: & [I might $]$ have \\
\hline 19 & & a piece of pizza so [it's fine. ] \\
\hline 20 & Mom: & [nods- $\uparrow$ yeah.] \\
\hline 21 & & puts box down-and plus we have focaccia \\
\hline 22 & Kara: & sing-songy voice-foca::ccia. \\
\hline 23 & & $(2.5)$ \\
\hline
\end{tabular}

After Mom and Kara decide on the type of spaghetti to use for their recipe, Jen initiates an information request sequence with a yes/no question in line 12, asking whether the pasta they've chosen is enough for all three of them. In response to this, Mom does an inscribed object check in lines 13 and 14. Her verbal response is preceded by a pause (line 13) where she flips over and gazes down at the pasta box she is holding. In line 14, Mom does a reading aloud with a reported speech structure, beginning with "It says." In cases of unpolarized yes/no questions, the unmarked answer is generally an unconditional affirmation or disaffirmation (Robinson, 2020). In this case, Mom's response is not a simple yes or no, but a clausal statement. Given that there are three people planning to eat this meal, the information provided in Mom's turn in line 13 is arguably a satisfactory answer to Jen's question, and Jen treats it as such in line 16 ("Okay"). As Jen responds, Mom moves her gaze to Jen, marking an end to the inscribed object check (line 15). Instead of closing the sequence, Mom elaborates on her response in line 17 ("so, it won't be a huge portion?"). This provides us with an example of an inscribed object check occurring in the immediate response turn, but the being elaborated on in a sequence expansion. The reading aloud of the recipe provides information ("serving size three") that leads Mom to draw conclusions about the extent to which there is enough pasta for everyone. As Mom completes her turn in line 17, Jen's next turn further accepts Mom's answer as not just fulfilling her information request but also unproblematic in the greater scheme of the task at hand. She doesn't need a lot of pasta because she is also planning to eat something else. Mom provides another reason why this amount of pasta is not problematic (they have focaccia; line 21) and the topic closes as a lapse ensues.

In the two extracts above, participants do inscribed object checks in immediate next turns after an information request sequence is initiated. In the first extract, Kara's inscribed object check provides a fitting second pair part to a wh- question, while Mom's turn in the second extract provides a second pair part to a yes/no question. A comparison of these two extracts reveals some of the variations in turn format that inscribed object checks can take in immediate next turns. First, while both inscribed object checks are initiated nonverbally with body and gaze movement, only Kara's initiation in the first extract is accompanied by some verbal marker. In the second extract, Mom's embodied initiation of the turn is done in silence, with no audible turn-holding mechanisms (e.g., "um"). Across the seven cases where participants do inscribed object checks in immediate 
next turns following information requests, all are initiated by the participant moving to the phone or other recipe object. These embodied pre-beginnings sometimes stand alone and are only occasionally accompanied by verbal markers, such as "um," "hold on," or "lemme check." Another interesting variation across these cases is the form that the recipe reading takes. In the first extract, for example, Kara reads a short phrasal excerpt from the recipe; however, in other cases, the speaker provides a longer clausal response by reading an entire line from the recipe (usually with imperative syntax). In these cases, the requested information is included amongst additional information that is less immediate. In the second extract, in contrast, Mom precedes the reading aloud with a phrase to mark reported speech. In addition to taking various turn formats, we have seen that these inscribed object checks have varied consequences for the ensuing interaction. In the first extract, the inscribed object check provides the requested information and the response is not elaborated further. In the second extract, the participant who employs the inscribed object check goes on to elaborate on her answer, initiating a short sequence expansion.

In both of the extracts analyzed above, participants answering the information request treat the recipe text or cooking instructions as a resource even though the inscribed object is not explicitly invoked in the question turn. By turning to the recipe text in the course of their response, they position the text as a resource, demonstrate their own unknowing epistemic stance, and treat the writer of the recipe text as the holder of ultimate epistemic authority. In both cases, the question appears to be directed at the person who has the most immediate physical access to the inscribed information. It is unclear whether the question-asker asserts $\mathrm{K}+$ epistemic expectations on the recipient, or simply select the recipient as a kind of go-between: the one who can most easily access and share the knowledge on the inscribed object. Regardless of the question-askers' intentions, the respondent in both cases treats the recipe text as having more epistemic rights than herself, and this plays out in the respondents' verbal and embodied actions in the ensuring turn(s).

\section{Inscribed Object Checks in Expanded Sequences}

Inscribed object checks can also be found in expanded information request sequences, specifically when the original response turn is treated as problematic in some way. In the following extract, both Jen and Mom are standing by the stove. They have been working on various cooking tasks in silence. At the start of the extract, Mom has a handful of pasta, which she is beginning to place into a pot of boiling water. Jen seems to be attending to Mom's current course of action because Jen moves her finger on the stovetop timer as she asks a question about how long to cook the pasta.

\begin{tabular}{|c|c|c|}
\hline \multicolumn{3}{|c|}{ Extract 3: Three minutes } \\
\hline 01 & Jen: & finger to timer-what is the timer. \\
\hline 02 & & presses button- $(0.2)$ \\
\hline 03 & & $>$ what do I put on the timer. $<$ \\
\hline 04 & Mom: & I don't know y[et. ] \\
\hline 05 & Jen: & [thre]e minutes? \\
\hline 06 & Mom: & I don't know ye(h)t.= \\
\hline 07 & Jen: & $=>$ well didn't you say it says three minutes? $<$ \\
\hline 08 & Mom: & raises hand $->$ yea- $<\mathrm{I} \uparrow$ think three minutes \\
\hline 09 & & [but I don't know for \\
\hline 10 & Jen: & [ok $\uparrow$ ay. $>$ then I'm just gonna-<] \\
\hline
\end{tabular}




\begin{tabular}{|c|c|c|}
\hline 11 & & presses button \\
\hline 12 & Mom: $\rightarrow$ & reaches for pasta box-so:rry i was [gonna] check, \\
\hline 13 & Jen: & [kay. ] \\
\hline 14 & & [now I need to take out- ] \\
\hline 15 & Mom: $\rightarrow$ & [holds box in front of face \\
\hline 16 & $\rightarrow$ & gazing at box-three to four- no. two to three. For: \\
\hline 17 & $\rightarrow$ & [refri ]gerated.=lowers box \\
\hline 18 & Jen: & {$[>$ kay. $<]$} \\
\hline 19 & & I'm gonna do:, presses buttons on stove \\
\hline 20 & Mom: & starts walking away from stove \\
\hline 21 & & yeah, \\
\hline
\end{tabular}

Jen initiates an information request sequence by asking a $w h$-question in line 01 . When Mom provides no immediate response, she repeats a somewhat expanded version of the question at a fast pace (line 03). In line 04, Mom responds to Jen's request by providing a nonanswer, accounting for her inability to answer by claiming a lack of knowledge. This nonanswer does not provide Jen with the information she seeks. Jen follows up by proposing, through a post-expansion, a candidate answer in line 05 ("three minutes?"). This effectively simplifies Mom's information-providing task as she now only needs to give a yes/no response. Instead, however, Mom repeats her original nonanswer with laughter (line 06). Jen then more directly challenges Mom's nonanswer and, specifically, her lack of knowledge. She refers to some past action of Mom's, which seems to imply that Mom knew this answer in the past, and should therefore know it now (line 07). Jen's question form ("didn't you...") prefers an affirmative response, which Mom begins to give in line 08. She then revises her response (lines 08 and 09) to demonstrate a weaker epistemic stance. She puts stress on the verb "think" and explicitly refers to her lack of certainty when she claims: "but I don't know for sure." At this point, Mom is still in the process of breaking up the pasta and placing it in the pot. Jen's response in line 10 appears to finally accept Mom's uncertain response as she moves to set the timer.

Although Jen accepts Mom's response as sufficient to begin completing the desired action (timer setting), and even moves on to discussing the next step in the cooking process ("now I need to take out-" in line 14), the sequence does not close here. In line 12, Mom apologizes and explicitly states her plan to "check." Her use of the past tense suggests that this checking was something she had been intending to do. And indeed, Mom's "yet" in lines 04 and 06 seem to preview her later recipe check. As Mom states this in line 12, she begins reaching for the pasta box on the counter next to her. This marks the onset of her inscribed object check. She gazes at the pasta box as she holds it up near her face (line 15) and, after a self-repair, provides the information Jen requested: "two to three. For refrigerated." Interestingly, although Jen had begun to move on to a new topic, she accepts Mom's revised response with "> kay. $<$ " in line 18 and returns to the timer setting task to adjust the time. Similar to Kara in the first extract, Mom provides a short phrasal response during her inscribed object check that seems closely aligned with Jen's initial "what" question. She provides a bit of extra information when she specifies that the time is for refrigerated pasta. We can see that Jen accepts Mom's response even before this is added as she seems to orient to the specific information she seeks and nothing extra. After Mom's inscribed object check and Jen's verbal and embodied acceptance of the information, the sequence closes as Mom walks away from the stove and Jen opens the oven to check on another dish in progress. 
This extract provides a more complex example of how an inscribed object check can provide a satisfactory response in an information request sequence. Unlike the first two extracts, the checking done here does not immediately follow the first pair part in the request sequence. Instead, Mom expresses an inability to provide the requested information but a plan to do so in the future, which initiates an expansion of the sequence as Jen repeatedly challenges Mom's answer and her assertion of lack of knowledge. Although Jen moves to close the sequence without having received an entirely satisfactory response, Mom keeps it open until she can perform the recipe check. As in the previous cases, we see that the participant selected to provide the information demonstrates a weak epistemic stance, but this time, it is more explicit. The recipe itself is again positioned as a resource for resolving issues with epistemic authority, as Mom's final response has no indicators of uncertainty (lines 16-17).

In the above extract, Mom's original second pair part in the information request sequence is a nonanswer, which fails to provide the sought-after response and keeps the sequence open. In other cases, a participant does provide a response, but that response is treated by others as unsatisfactory. The final extract provides an example of this. As the extract begins, Kara has been commenting on how she wants to dice the garlic, which goes against the recipe instructions to slice them. Mom asks a question beginning in line 03, which marks a stepwise topic shift.

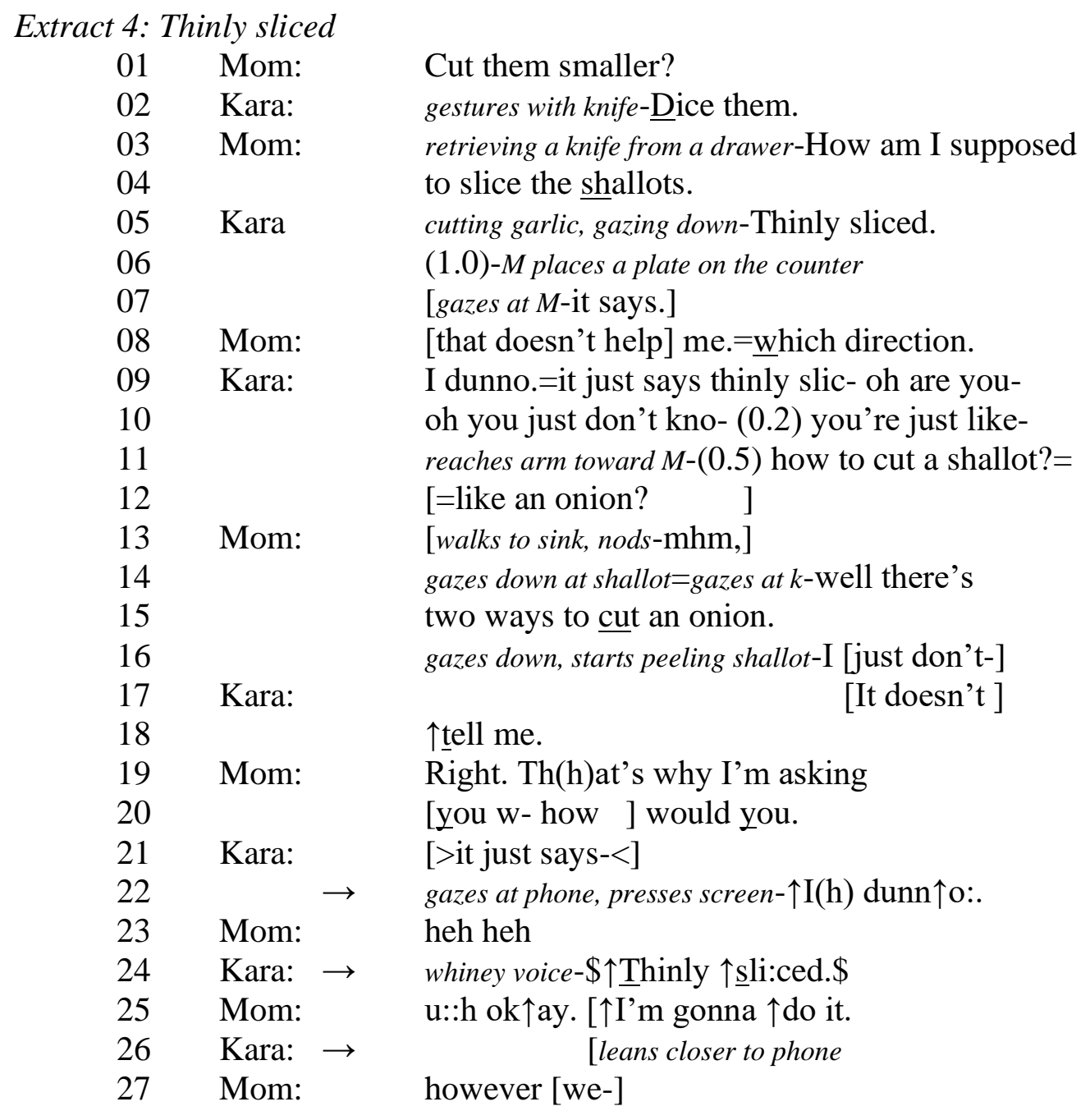




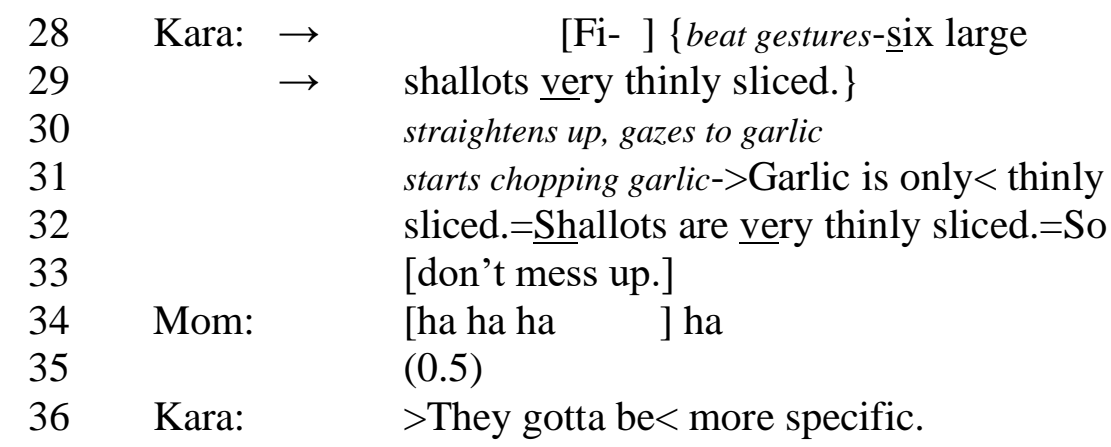

Mom initiates an information request sequence in lines 03 and 04 by asking a $w h$ - question: "How am I supposed to slice the shallots." Her stress on "shallots" suggests a contrast with the just prior discussion of slicing garlic. Her use of the modal verb "supposed to" is interesting in that "supposed to" seems to refer to the authority of something (like an established rule) beyond that of her directed participant (compare this to a more personal "should"). Kara responds immediately in her next turn with a simple, "thinly sliced" (line 05 ). Her phrasal answer appears to provide the adverbial information Mom has requested, and it is done in a preferred format with falling intonation and no indicators of trouble. Mom does not immediately respond as she sets a plate on the counter (line 06). Kara then adds an increment to her response ("it says.") which changes her response in an interesting way. Kara's footing in her original "thinly sliced" is ambiguous in that it is unclear whether she or the recipe text itself is the author of her response (Goffman, 1981). By adding "it says", she makes it clear that although she is not currently checking the recipe but engaged in a different task, this information comes directly from the recipe. This appears to be one way that Kara strengthens the epistemic authority of her claim after her response is not immediately taken up by Mom.

At the same time that Kara adds an increment, Mom challenges her original response, claiming that the information she provided is not helpful (line 08). This initiates a sequence expansion. She specifies the meaning of "how" in her question-"which direction." Kara then provides a nonanswer ("I dunno.") and begins to repeat her claim of what the recipe says (line 09). She then shifts to trying to get Mom to clarify the nature of the information she seeks (09-11). She proposes another answer with rising intonation: "like an onion?" Mom does not accept this answer either (lines 14-15). Kara then claims emphatically that, "it doesn't tell me", providing an account for her inability to adequately respond to Mom's revised request for information. While Kara seems focused on specifically what the recipe says, Mom shifts to pursuing an answer from Kara's own perspective. She accepts Kara's claim that the recipe cannot provide the requested information and stresses "you" as she initiates another question.

Kara, however, continues to orient to the information provided by the recipe ("it just says" in line 21), and she reaches for and moves her gaze to her phone. As she does this, she repeats her personal nonanswer ("I dunno") with laughter. This marks the beginning of Kara's inscribed object check: moving toward the phone while repeating her claim of lack of knowledge. As Mom continues to laugh, Kara repeats her original answer in a smiley and whiney voice (line 24). It is unclear whether she is reading this verbatim from her phone or saying this as she searches for the place in the recipe. At this point, Mom appears to accept Kara's response and expresses her intent to begin doing the step. Kara continues to gaze at her phone, moving even closer. In lines 28 and 29, after a false start, she appears to read from the recipe, word for word: "six large shallots very thinly sliced." (See Appendix B). The added stress on "very" seems to mark this as new 
information, and this is indeed the only additional information that this recipe check provides in response to Mom's initial "how" question. Kara marks the end of her inscribed object check by straightening up and returning to her garlic cutting task. As she starts cutting, she comments on the difference between cutting garlic and shallots and warns Mom not to "mess up," which Mom treats as humorous. After a lapse in the talk, Kara comments on the lack of specificity in the recipe, and Mom turns to another person who has just entered the kitchen to ask him whether he likes shallots.

This extract provides an even more complex example of the role of inscribed object checks in information request sequences where task-related knowledge is distributed among participants and inscribed objects. Although Mom selects Kara as the recipient of her request for information, she originally seems to be seeking information that the recipe provides, evident in her use of the authoritative modal "supposed to." This initiates a multi-turn sequence where Mom shifts her question to place Kara in the position of having the epistemic rights to answer the question. This is a position which Kara never accepts, continuing to orient to the recipe as expert. Even when Mom moves to close the sequence, essentially giving up on her information pursuit (line 25), Kara persists and employs an inscribed object check. This is similar to Extract 3 in that the initiator of the original information request sequence accepts a not-so-satisfying answer, but the respondent persists with the recipe checking. Unlike Extract 3, where the respondent immediately demonstrates uncertainty and a desire to check the recipe, the respondent in Extract 4 originally presents her response as sufficient. It is only once this response is continually challenged, that she engages in a recipe check. In this final example, the speaker who employs the inscribed object check follows it with an explanation and comment in her own words before the sequence is closed. Her final comments suggest that, unlike the previous cases, the recipe text has failed to adequately close the knowledge gaps made relevant by the information request.

\section{DISCUSSION AND CONCLUSION}

This analysis has shown how participants make relevant an inscribed object in their immediate environment during information request sequences. They do this by employing a particular embodied practice of checking and reading aloud a recipe. In the environment of jointly preparing food, participants orient to the forward progression of the current activity by asking information-seeking questions about the cooking process. By requesting information, the speaker makes known their own lack of knowledge and, potentially, their expectation that the recipient is able to provide the requested information (Heritage \& Raymond, 2012). In settings like this one, where all participants have similar unknowing stances regarding the task at hand, they may look to inscribed objects in their immediate environment to address emerging knowledge gaps. Therefore, even when an information-seeking question is directed at a particular participant, that participant may not be able and nor expected to respond based on their current knowledge status. Instead, as we saw in the above extracts, the respondent can employ inscribed object checks at different points in the sequence for help to provide the desired information and close the knowledge gaps.

Information request sequences with inscribed object checks can take a variety of forms. At its most basic, a respondent can immediately engage in an inscribed object check after the request initiation. This places the requested information in the immediate next turn, often after some within-turn delay, and leads to sequence closure. In other cases, the respondent employs an inscribed object check only after their initial second pair part is challenged and the sequence is expanded. In the third extract, for instance, the respondent seems to immediately indicate uncertainty and a desire to check the recipe but is delayed because she is engaged in another 
embodied task (putting pasta in water). In the fourth extract, on the other hand, the speaker does not initially indicate trouble with her response turn, but the other participant does. We can observe that, in these expanded sequences, when the object check is not done immediately, the original answer is challenged in some way, either by the responder herself or by the question-asker. In all four cases, the information request sequence closes immediately or shortly after the inscribed object check is employed. Interestingly, in the last two cases, even as one participant moves to close the sequence, the other one keeps it open long enough to do the recipe check.

From the perspective of epistemics, the extracts reviewed above provide strong evidence that participants orient to the recipe documents as holding a relative $\mathrm{K}+$ status in the interaction. We see this when participants immediately check the recipe before providing a response (Extracts 1 and 2). We also see evidence of this when participants follow unknowing responses (Extract 3) or challenges to their response (Extract 4) with recipe checks. The analysis has also revealed specific linguistic evidence of an orientation to the recipe documents as resources for displaying epistemic stance and altering epistemic status. For example, when Kara follows her response to an information request with the increment "it says," she bolsters the epistemic strength of her claim. Another example is in Mom's initial information request in Extract 4 ("How am I supposed to slice the shallots"), where "supposed to" points to some kind of authority (compare this with "should"). Finally, we see orientation to the recipe texts as resources for moving from an unknowing to knowing status when Mom claims that she doesn't know "yet" in Extract 3, suggesting that, in her initial response turn when she is not engaged in recipe checking, she still intends to check the document in order to answer Jen's question even before Jen challenges her response.

These findings contribute to research on request sequences by specifying a particular type of embodied response turn. They show how participants draw on verbal, embodied, and environmental resources to fulfill a request when the participants hold relatively unknowing epistemic statuses regarding the collaborative task at hand, and when requested information lies in inscribed objects in the immediate environment. In settings where participants are engaged in joint problem-solving activities, like cooking an unfamiliar dish, speakers may ask each other questions with full understanding that the answers they seek are found in some inscribed object in the surrounding environment. Further research on the role of objects in interaction should continue to move beyond institutional settings, exploring other contexts where participants draw on the affordances of their environment to achieve everyday tasks. It should be noted that, of the 35 cases of inscribed object checks in my data, only 16 appeared within information request sequences. Additional research is needed to understand the other roles that this practice plays in interaction. To conclude, a turn-by-turn analysis of the how participants coordinate collaborative task performance while attending to diverse and often fluid epistemic statuses contribute to our efforts to characterize the social order of these settings. In the case of an informal cooking activity, this analysis has revealed that, unless otherwise agreed upon, recipes are expected to be followed, and this expectation has consequences for how interactions during this task unfold.

\section{REFERENCES}

Back, M. (2016). Epistemics and expertise in peer tutoring interactions: Co-constructing knowledge of Spanish. The Modern Language Journal, 100(2), 508-521. https://doi.org/10.1111/modl.12334 
Bourgeois, M. S. (1990) Enhancing conversation skills in patients with Alzheimer's disease using a prosthetic memory aid. Journal of Applied Behavior Analysis, 23(1), 29-42. https://doi.org/10.1901/jaba.1990.23-29

Bourgeois, M. S. (1992) Evaluating memory wallets in conversations with persons with dementia. Journal of Speech, Language, and Hearing Research, 35(6), 1344-1357. https://doi.org/10.1044/jshr.3506.1344

Cekaite, A. (2010). Shepherding the child: Embodied directive sequences in parent-child interactions. Text \& Talk, 30(1), 1-25. https://doi.org/10.1515/text.2010.001

Clayman, S. E. (2002). Sequence and solidarity. In E. J. Lawler, \& S. R. Thye (Eds.), Advances in group processes: Group cohesion, trust, and solidarity (pp. 229-253). Elsevier Science.

Couper-Kuhlen, E., Fox, B., Thompson, S. A. (2011, July). Social action construction: Responding to requests. Paper presented at the 12th International Pragmatics Conference, Manchester, UK.

Curl, T., \& Drew, P. (2008). Contingency and action: A comparison of two forms of requesting. Research on Language \& Social Interaction, 41(2), 129-153. https://doi.org/10.1080/08351810802028613

Day, D., \&Wagner, J. (2014) Objects as tools for talk. In M. Nevile, P. Haddington, T. Heinemann, \& M. Rauniomaa (Eds.), Interacting with objects: Language, materiality, and social activity (pp. 101-123). John Benjamins.

Deppermann, A., Schmitt, R., \& Mondada, L. (2010) Agenda and emergence: Contingent and planned activities in a meeting. Journal of Pragmatics, 42(6), 1700-1718. https://doi.org/10.1016/j.pragma.2009.10.006

Ford, C. E. (1999). Collaborative construction of task activity: Coordinating multiple resources in a high school physics lab. Research on Language and Social Interaction, 32(4), 369-408. https://doi.org/10.1207/S15327973rls3204_3

Fox, B. A., \& Thompson, S. A. (2010). Responses to wh-questions in English conversation. Research on Language and Social Interaction, 43(2), 133-156. https://doi.org/10.1080/08351811003751680

Goffman, E. (1981). Forms of talk. University of Pennsylvania Press.

Goodwin, C. (2000). Practices of color classification. Mind, Culture, and Activity, 7(1-2), 19-36. https://doi.org/10.1080/10749039.2000.9677646

Greer, T., \& Leyland, C. (2020). Inscribed objects as resources for achieving progressivity in lesson planning talk. Journal of Applied Linguistics and Professional Practice, 14(2), 200229. https://doi.org/10.1558/jalpp.33667

Hamann, M. G. T. (2020). Using written information to answer questions in rehabilitation after traumatic brain injury. Journal of Applied Linguistics and Professional Practice, 14(2), 230255. https://doi.org/10.1558/jalpp.33620

Heritage, J. (1984), A change-of-state token and aspects of its sequential placement. In J. M. Atkinson, \& J. Heritage (Eds.), Structures of social action: Studies in conversation analysis (pp. 299-345). Cambridge University Press.

Heritage, J. (1998). Oh-prefaced responses to inquiry. Language in Society, 27, 291-334. https://doi.org/10.1017/S0047404500019990

Heritage, J. (2012). Epistemics in action: Action formation and territories of knowledge. Research on Language and Social Interaction, 5, 1-29. https://doi.org/10.1080/08351813.2012.646684 
Heritage, J. (2013). Epistemics in conversation. In J. Sidnell \& T. Stivers (Eds.), Handbook of conversation analysis (pp. 370-94). Wiley-Blackwell.

Heritage, J., \& Raymond, G. (2012). Navigating epistemic landscapes: Acquiescence, agency and resistance in responses to polar questions. In J. P. de Ruiter (Ed.), Questions: Formal, functional and interactional perspectives (pp. 179-192). Cambridge University Press.

Jakonen, T., \& Morton, T. (2015). Epistemic search sequences in peer interaction in a contentbased language classroom. Applied Linguistics, 36(1), 73-94. https://doi.org/10.1093/applin/amt031

Keevallik, L. (2011). 'The terms of not knowing. In T. Stivers, L. Mondada, \& J. Steensig (Eds.), The morality of knowledge in conversation (pp. 184-206). Cambridge University Press.

Lee, S. H. (2011). Managing non-granting of customers' requests in commercial service encounters. Research on Language and Social Interaction, 44(2), 109-134. https://doi.org/10.1080/08351813.2011.567091

Mondada, L. (2006). Participants' online analysis and multimodal practices: Projecting the end of the turn and the closing of the sequence. Discourse Studies, 8(1), 117-129. https://doi.org/10.1177/1461445606059561

Mondada, L. (2011). The organization of concurrent courses of action in surgical demonstrations. In J. Streeck, C. Goodwin, \& C. LeBaron (Eds.), Embodied interaction: Language and body in the material world (pp. 207-226). Cambridge University Press.

Mondada, L. (2016). Challenges of multimodality: Language and the body in social interaction. Journal of Sociolinguistics, 20(2), 2-32. https://doi.org/10.1111/josl.1_12177

Nevile, M. (2004). Integrity in the airline cockpit: Embodying claims about progress for the conduct of an approach briefing. Research on Language and Social Interaction, 37(4), 447480. https://doi.org/10.1207/s15327973rlsi3704 3

Nevile, M. (2015). The embodied turn in research on language and social interaction. Research on Language and Social Interaction, 48(2), 121-151. https://doi.org/10.1080/08351813.2015.1025499

Nevile, M., Haddington, P., Heinemann, T., \& Rauniomaa, M. (2014). On the interactional ecology of objects. In M. Nevile, P. Haddington, T. Heinemann, \& M. Rauniomaa, (Eds.), Interacting with objects: Language, materiality and social activity (pp. 3-26). John Benjamins.

Nissi, R., \& Lehtinen, E. (2015). Conducting a task while reconstructing its meaning: Interaction, professional identities and recontextualization of a written task assignment. Pragmatics, 24(3), 393-423. https://doi.org/10.1075/prag.25.3.04nis

Pomerantz, A. (1984). Agreeing and disagreeing with assessments: Some features of preferred/dispreferred turn shapes. In M. Atkinson \& J. Heritage (Eds.), Structures of social action (pp. 57-101). Cambridge University Press.

Pomerantz, A. (1988). Offering a candidate answer: An information seeking strategy. Communication Monographs, 55(4), 360-373.

Rauniomaa, M., \& Keisanen, T. (2012). Two multimodal formats for responding to requests. Journal of Pragmatics, 44(6-7), 829-842. https://doi.org/10.1016/j.pragma.2012.03.003

Raymond, G. (2003). Grammar and social organization: Yes/no interrogatives and the structure of responding. American Sociological Review, 68, 939-967. https://doi.org/10.2307/1519752

Richardson, E., \& Stokoe, E. (2014). The order of ordering. In M. Nevile, P. Haddington, T. Heinemann, \& M. Rauniomaa, (Eds.), Interacting with objects: Language, materiality and social activity (pp. 31-56). John Benjamins. 
Robinson, J. D. (2020). Revisiting preference organization in context: A qualitative and quantitative examination of responses to information seeking. Research on Language and Social Interaction, 53(2), 197-222. https://doi.org/ 10.1080/08351813.2020.1739398

Sacks, H. (1987). On the preferences for agreement and contiguity in sequences in conversation. In G. Button \& J. R. E. Lee (Eds.), Talk and social organization (pp. 54-69). Multilingual Matters.

Schegloff, E. A. (1996). Turn organization: One intersection of grammar and interaction. In E. Ochs, E. A. Schegloff, \& S. A. Thompson (Eds.), Interaction and grammar (pp. 52-133). Cambridge University Press.

Schegloff, E. A. (2007). Sequence organization in interaction: A primer in conversation analysis (Vol. 1). Cambridge University Press.

Sorjonen, M. L. (2001). Responding in conversation: A study of response particles in Finnish. John Benjamins.

Stivers, T. (2010). An overview of the question-response system in American English conversation. Journal of Pragmatics, 42(10), 2772-2781. https://doi.org/10.1016/j.pragma.2010.04.011

Stivers, T. (2011). Morality and question design: 'Of course' as contesting a presupposition of askability. In T. Stivers, L. Mondada, \& J. Steensig (Eds.), The morality of knowledge in conversation (pp. 82-106). Cambridge University Press.

Stivers, T., \& Hayashi, M. (2010). Transformative answers: One way to resist a question's constraints. Language in Society, 39(1), 1-25. https://doi.org/10.1017/S0047404509990637

Stivers, T., \& Robinson, J. D. (2006). A preference for progressivity in interaction. Language in society, 35(3), 367-392. https://doi.org/10.1017/S0047404506060179

Streeck, J., Goodwin, C., \& LeBaron, C. (2011). Embodied interaction in the material world: An introduction. In J. Streeck, C. Goodwin, \& C. LeBaron (Eds.), Embodied interaction: Language and body in the material world (pp. 1-26). Cambridge University Press.

Svennevig, J. (2012). The agenda as resource for topic introduction in workplace meetings. Discourse Studies, 14(1), 53-66. https://doi.org/10.1177/1461445611427204

Svinhufvud, K., \& Vehvilainen, S. (2013). Papers, documents, and the opening of an academic supervision encounter. Text \& Talk, 33(1), 139-166. https://doi.org/10.1515/ text-2013-0007 


\section{APPENDIX A}

\section{CA Transcription Notations}

$?$

$?$

,

$-$

$\because:$

Word

Word

WORD

${ }^{\circ}$ word $^{\circ}$

$\uparrow$ word

$\downarrow$ word

$>$ word<

$<$ word>

$<$

hh

.hh

(hh)

[ ]

[]

$=$

(.)

()

words

\{words-words $\}$

(try 1$) /(\operatorname{try} 2)$

\$word\$

\#word\#

SS (period) falling intonation.

(question mark) rising intonation.

(comma) continuing intonation.

(hyphen) abrupt cut-off.

(colon(s)) prolonging of sound.

(underlining) stress.

The more underlining, the greater the stress.

(all caps) loud speech.

(degree symbols) quiet speech.

(upward arrow) raised pitch.

(downward arrow) lowered pitch.

(more than and less than) quicker speech.

(less than \& more than) slowed speech.

(less than) jump start or rushed start.

(series of h's) aspiration or laughter.

(h's preceded by dot) inhalation.

(h's in parentheses) inside word boundaries.

(lined-up brackets) beginning and ending of

simultaneous or overlapping speech.

(equal sign) latch or contiguous utterances of the same speaker.

(number in parentheses) length of a silence in 10ths of a second.

(period in parentheses) micro-pause, 0.2 second or less.

(empty parentheses) non-transcribable segment of talk.

(italics and small font) non-speech activity

dash to indicate co-occurrence of nonverbal behavior and verbal

elements; curly brackets to mark the beginning and ending of such

co-occurrence if necessary; $\sim$ in place of dash to indicate the beginning of talk in the midst of nonverbal conduct.

(two parentheses separated by a slash) alternative hearings.

(dollar or pound signs) smiley voice.

(number signs) squeaky voice.

students 


\section{APPENDIX B}

Recipe

Caramelized Shallot Pasta

Alison Roman

https://cooking.nytimes.com/recipes/1020830-caramelized-shallot-pasta

Ingredients

$1 / 4$ cup olive oil

6 large shallots, very thinly sliced

5 garlic cloves, 4 thinly sliced, 1 finely chopped

Kosher salt and freshly ground black pepper

1 teaspoon red-pepper flakes, plus more to taste

1 (2-ounce) can anchovy fillets (about 12), drained

1 (4.5-ounce) tube or (6-ounce) can of tomato paste (about $1 / 2$ to $3 / 4$ cup)

10 ounces pasta

1 cup parsley, leaves and tender stems, finely chopped

Flaky sea salt

Instructions

1. Heat olive oil in a large heavy-bottomed Dutch oven over medium high. Add shallots and thinly sliced garlic, and season with salt and pepper. Cook, stirring occasionally, until the shallots have become totally softened and caramelized with golden-brown fried edges, 15 to 20 minutes.

2. Add red-pepper flakes and anchovies. (No need to chop the anchovies; they will dissolve on their own.) Stir to melt the anchovies into the shallots, about 2 minutes.

3. Add tomato paste and season with salt and pepper. Cook, stirring constantly to prevent any scorching, until the tomato paste has started to cook in the oil a bit, caramelizing at the edges and going from bright red to a deeper brick red color, about 2 minutes. Remove from heat and transfer about half the mixture to a resealable container, leaving the rest behind. (These are your leftovers to be used elsewhere: in another batch of pasta or smeared onto roasted vegetables, spooned over fried eggs or spread underneath crispy chicken thighs.)

4. To serve, cook pasta according to package instructions in a large pot of salted boiling water until very al dente (perhaps more al dente than usual). Transfer to Dutch oven with remaining shallot mixture (or a skillet if you are using the leftover portion) and 1 cup pasta water. Cook over medium-high heat, swirling the skillet to coat each piece of pasta, using a wooden spoon or spatula to scrape up any bits on the bottom, until pasta is thick and sauce has reduced and is sticky, but not saucy, 3 to 5 minutes.

5. In a small bowl, combine parsley and finely chopped garlic clove, and season with flaky salt and pepper. Divide pasta among bowls, or transfer to one large serving bowl, and top with parsley mixture and a bit more red-pepper flakes, if you like. 